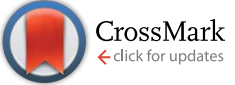

Cite this: RSC Adv., 2016, 6, 57253
Received 11th April 2016 Accepted 8th June 2016

DOI: 10.1039/c6ra09323j

www.rsc.org/advances

\section{Structure determination of organic aging products in lithium-ion battery electrolytes with gas chromatography chemical ionization mass spectrometry (GC-Cl-MS) $\dagger$}

\begin{abstract}
Martin Grützke, Waldemar Weber, Martin Winter and Sascha Nowak*
For Gas Chromatography Chemical Ionization Mass Spectrometry (GC-Cl-MS) method development, a standard lithium-ion battery (LIB) electrolyte was thermally aged at $95{ }^{\circ} \mathrm{C}$ for a faster generation of decomposition products. Interestingly, phosphorous containing aging products were preferably formed in the first hours. Furthermore, the organic containing aging products without phosphorous are formed after longer times. Since, these compounds are very similar in structure, molecular mass and consequently in their fragmentation during electron ionization (EI) experiments, chemical ionization was applied to identify the structure of the LIB electrolyte aging products. Herein, the results of the structure determination of organic LIB electrolyte aging products with $\mathrm{GC}-\mathrm{Cl}-\mathrm{MS}$ are presented. Furthermore, formation of the identified species and relative concentrations over a time period of 22 days were determined by using an internal standard.
\end{abstract}

\section{Introduction}

Lithium-ion batteries (LIBs) are the foundation of modern consumer electronics and portable devices. Furthermore, these energy storage systems are the most promising technology for electric and hybrid electric vehicles. Unfortunately, the lifetime of LIBs is limited due to electrochemical, thermal and calendric aging. ${ }^{1}$ State of the art electrolytes for LIBs usually consist of $\mathrm{LiPF}_{6}$ as a conducting salt dissolved in a mixture of different linear and cyclic organic carbonates, e.g. ethyl methyl carbonate (EMC) and ethylene carbonate (EC). ${ }^{20}$ Despite the chemical and thermal instability in organic carbonates towards the P-F bond, $\mathrm{LiPF}_{6}$ is the most commercial applied conducting salt today. ${ }^{2,3}$ In comparison to other applied salts, lithium hexafluorophosphate still has several advantages like high solubility in organic carbonates, high electrochemical stability and excellent solid electrolyte interphase (SEI) forming capabilities. $^{4-6}$ However, due to its thermal instability, hexafluorophosphate undergoes the decomposition to highly reactive $\mathrm{PF}_{5}$. As a consequence, numerous decomposition products are formed in LIB electrolytes and are an ongoing subject of investigations with different methods. The variety of decomposition products ranges from $\mathrm{HF}^{7-10,25}$ inorganic and organic phosphates (OPs), ${ }^{11-19,26} \mathrm{CO}_{2},{ }^{21,22}$ over dicarboxylates ${ }^{23,24}$

University of Münster, MEET Battery Research Center, Institute of Physical Chemistry, Corrensstrasse 46, 48149 Münster, Germany. E-mail: sascha.nowak@uni-muenster. de; Fax: +4925183 36032; Tel: +492518336735

$\dagger$ Electronic supplementary information (ESI) available. See DOI: 10.1039/c6ra09323j diols $^{8}$ and alkyl fluorides., ${ }^{9,12,21}$ Furthermore, the applied methods and corresponding reaction mechanisms are intensively discussed in the literature. ${ }^{13-18,27-40}$

One particular interesting group is the group of ethylene bridged carbonates and oligomeric alkoxy ethylene glycols. However, the clear identification of these compounds only with gas chromatography hyphenated to mass spectrometry (GC-MS) is challenging due to many compounds with identical molecular masses and very similar spectra obtained with electron ionization (EI). Structure determination has been performed by Gireaud et al. ${ }^{27}$ and Gachot et al. ${ }^{28}$ However, both used electrospray ionization (ESI)-HRMS based techniques. Within this work it was demonstrated, that sophisticated HRMS experiments are not mandatory and structure determination can be carried out by performing GC-MS with chemical ionization experiments without the need of another technique. To proof this approach, a standard electrolyte was thermally aged at 95 ${ }^{\circ} \mathrm{C}$ for a faster generation of decomposition products as sample for GC-CI-MS method development. The thermal electrolyte aging leads to the same aging products as electrochemical aging and can therefore carried out in this manner. , $^{8,13,14,27,28,30,35,37}$ Besides dimethyl-2,5-dioxahexane dicarboxylate (DMDOHC), ethyl methyl-2,5-dioxahexane dicarboxylate (EMDOHC) and diethyl-2,5-dioxahexane dicarboxylate (DEDOHC), clear structure determination of several other LIB electrolyte aging products was achieved with GC-CI-MS. Interestingly, phosphorous containing aging products were preferably formed in the first hours. Nevertheless, the results of their structure determination after aging of 48 hours have recently been published by Weber 

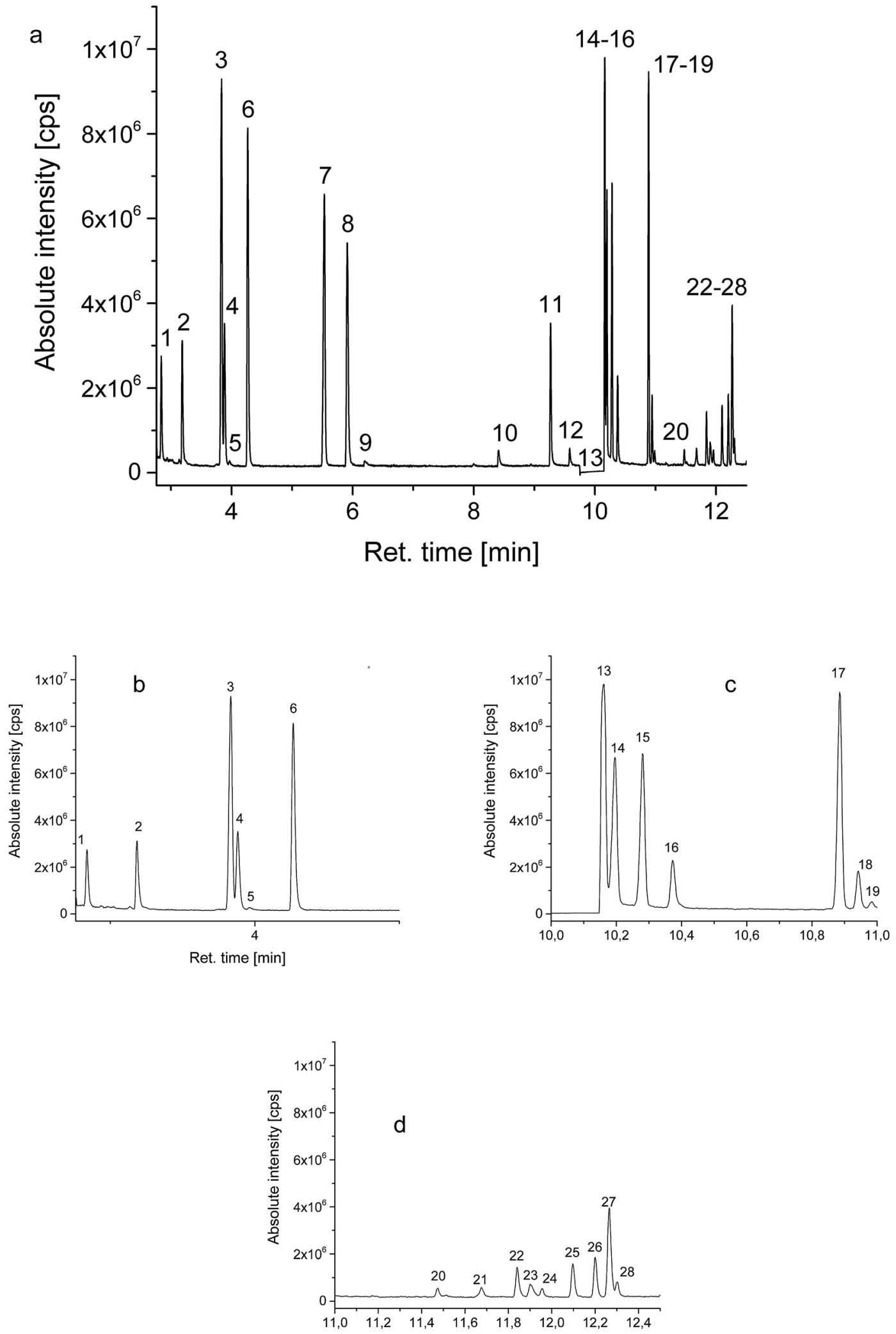

Fig. 1 (a) Chromatogram (GC-MS) of LP50 electrolyte (EMC/EC, 1 mol L ${ }^{-1}$ LiPF 6 ), which was thermally aged for 22 days at $95{ }^{\circ} \mathrm{C}$ in gas-tight aluminum vials. The figures below $(b-d)$ show the enlarged regions of interest, $(b-d)$ enlargement for the regions $0-5$ min (b), 10-11 min (c) and 11-12.5 $\min (d)$. 
et al. ${ }^{15}$ Organic containing aging products without phosphorous are formed after longer times of thermal treatment. Herein, the results of the structure determination of organic LIB electrolyte aging products with GC-CI-MS for the same sample after aging of several weeks are presented. Furthermore, formation of the identified species and relative concentrations over a time period of 22 days were determined by using an internal standard (IS). The identified compounds which are presented in this work are the result of aging reactions of the different constituents of the electrolyte solvent with each other.

\section{Experimental}

\subsection{Chemicals and materials}

LP50 (EMC/EC, $1 \mathrm{~mol} \mathrm{~L}^{-1} \mathrm{LiPF}_{6}$, battery grade) from BASF and dichloromethane (99.9\%) from VWR were used. Tris(2,2,2trifluoroethyl) phosphate (pure according to NMR) which was used as IS was synthesized in the working group of Prof. Dr Gerd-Volker Röschenthaler at the Jacobs University of Bremen. The GC was run with helium (purity 6.0) as carrier gas and $\mathrm{NH}_{3}$ (purity 3.8) for CI experiments, both purchased from Westfalen Gas.

\subsection{Sample preparation}

$2 \mathrm{~mL}$ of the LP50 electrolyte were thermally aged for 22 days at $95{ }^{\circ} \mathrm{C}$ in $10 \mathrm{~mL}$ aluminum vials with butyl/PTFE caps. After certain times, $25 \mu \mathrm{L}$ of the sample were transferred into a $2 \mathrm{~mL}$ PP Safe-Lock tube, spiked with $5 \mu \mathrm{L}$ IS and diluted with $1 \mathrm{~mL}$ dichloromethane. After centrifugation at $8500 \mathrm{rpm}$ for 5 minutes, the clear solution was investigated with GC-MS without the centrifuged solid $\mathrm{LiPF}_{6}$. Independent samples were used for each data point in the time depending investigations.

\subsection{GC-CI-MS setup}

GC-MS experiments were carried out on a Shimadzu GCMSQP2010 Ultra equipped with an AOC-5000 Plus autosampler and an OPTIC-4 injection system. GCMS Real Time Analysis and GCMS Postrun Analysis were used for setup control and data analysis. The OPTIC-4 injector was controlled and monitored with the Evolution Workstation software. EI, PCI and NCI were measured with a combined ion source. $\mathrm{NH}_{3}$ (introduced with 3 bar) was used for CI experiments. $1 \mu \mathrm{L}$ of the diluted samples was injected at an injection temperature of $230{ }^{\circ} \mathrm{C}$ onto a Restek Rxi-5ms column $(30 \mathrm{~m} \times 0.25 \mathrm{~mm} \times 0.25 \mu \mathrm{m})$ with a deactivated guard-column $(5 \mathrm{~m} \times 0.25 \mathrm{~mm})$. The system was run with helium as carrier gas with a column flow of $1 \mathrm{~mL} \mathrm{~min}^{-1}$, a split of $1: 10$ and the following column oven program: starting with $40{ }^{\circ} \mathrm{C}$ for $1 \mathrm{~min}$, the temperature was increased with a rate of $3{ }^{\circ} \mathrm{C} \mathrm{min}{ }^{-1}$ to $60{ }^{\circ} \mathrm{C}$ and then with $30{ }^{\circ} \mathrm{C} \mathrm{min}^{-1}$ to $230{ }^{\circ} \mathrm{C}$. It was measured in a range of $\mathrm{m} / \mathrm{z}=30-400$ with an event time of $0.1 \mathrm{~s}$ at an interface temperature of $250{ }^{\circ} \mathrm{C}$, an ion source temperature of $200{ }^{\circ} \mathrm{C}$, a filament voltage of $70 \mathrm{~V}$ and a detector voltage which was chosen relative to the current tuning result. An additional injector and column with a flow of $0.6 \mathrm{~mL} \mathrm{~min}^{-1}$ was connected via a T-fitting with the used column to the same MS-detector. Thus, the absolute column flow at the MS entrance was $1.6 \mathrm{~mL} \mathrm{~min}^{-1}$.

For the time depending GC-MS experiments a Perkin Elmer GC-MS Clarus 600 with a polar Restek Stabilwax column (30 m $\times 0.25 \mathrm{~mm} \times 0.25 \mu \mathrm{m}$ ) was used. TurboMass 5.4.2 and Clarity software were used for setup control and data analysis. The injection temperature was $210{ }^{\circ} \mathrm{C}$. The column flow was $1 \mathrm{~mL}$ $\min ^{-1}$ with the same split, column and column oven program as just described above. The mass spectrometer was run with a detector voltage of $1.5 \mathrm{kV}$. Masses were recorded between $m / z=30-350$. The following specific fragments were used in SIM mode for relative concentration monitoring over time: IS $(115 \mathrm{~m} / \mathrm{z}), \mathbf{6}(72 \mathrm{~m} / \mathrm{z}), \mathbf{8}(74 \mathrm{~m} / \mathrm{z}), \mathbf{1 1}(104 \mathrm{~m} / \mathrm{z}), \mathbf{1 2}(89 \mathrm{~m} / \mathrm{z}), \mathbf{1 4}$ (103 m/z), $15(91 \mathrm{~m} / \mathrm{z}), 17(91 \mathrm{~m} / \mathrm{z}), 18(103 \mathrm{~m} / \mathrm{z}), 22(103 \mathrm{~m} / \mathrm{z}), 23$ $(148 \mathrm{~m} / \mathrm{z}), 26(103 \mathrm{~m} / \mathrm{z})$ and $27(117 \mathrm{~m} / \mathrm{z})$.

\section{Results and discussion}

The thermally aged electrolyte was analyzed with GC-MS. The chromatogram measured with the EI setup is presented in Fig. 1.

A complex mixture of 28 compounds was separated with the applied method. In most cases, baseline separation could be

Table 1 Used organic carbonate solvents and identified aging compounds with the same masses corresponding to the chromatogram in Fig. 1

$M=88 \quad M=90 \quad M=104 \quad M=118$<smiles>C1COCCO1</smiles>

4<smiles>O=C1OCCO1</smiles>

13<smiles>COC(=O)OC</smiles><smiles>COCCOC</smiles>

2<smiles>CCOCCO</smiles>

5<smiles>CCOC(=O)OC</smiles><smiles>CCOC(=O)OCC</smiles><smiles>CCOCCOC</smiles><smiles>CCOCCOCC</smiles> 
achieved. Peaks 1, 3, 7 and 13 were assigned to DMC, EMC, DEC and EC. EMC and EC were used in the investigated electrolyte. At a retention time of around 10 minutes, the detector voltage was decreased to $0.7 \mathrm{kV}$ to improve the observability of the following compounds. Thus, the EC peak is not as sharp as in GC standard chromatograms. DMC and DEC are formed during aging in a trans-esterification reaction of EMC. ${ }^{34}$ For each of these four organic carbonates with different molecular masses, at least one other substance with the same mass could be observed in the thermally aged electrolyte of Fig. 1. Table 1 summarizes this substance group, whose compounds elute within the first six minutes.

Structure determination for compounds 2, 4, 5 and 8 was achieved by comparison of the measured EI spectra with the NIST 08 library. The EI spectrum of compound 6 did not match with an appropriate EI spectrum of this library. Thus, GC-CI-MS experiments with the same equipment and method were carried out. The $(\mathrm{M}+\mathrm{H})^{+}$and $\left(\mathrm{M}+\mathrm{NH}_{4}\right)^{+}$signals of the PCI spectra for compound 6 resulted in a molecular mass of 104. In combination with the three significant signals in the NCI spectrum (Fig. 2), which are $31 \mathrm{~m} / z$ for $\mathrm{CH}_{3} \mathrm{O}^{-}, 45 \mathrm{~m} / z$ for $\mathrm{CH}_{3} \mathrm{CH}_{2} \mathrm{O}^{-}$and $75 \mathrm{~m} / z$ for $\mathrm{CH}_{3} \mathrm{OCH}_{2} \mathrm{CH}_{2} \mathrm{O}^{-}$, only the structure of 1-ethoxy-2methoxy ethane is possible. EMC for example has the same molecular mass of 104 but different negative fragments. The binding energy of the $\mathrm{C}-\mathrm{O}$ bond in the $\mathrm{CO}_{3}$ structure element is stronger compared to the $\mathrm{C}-\mathrm{O}$ bond in the $\mathrm{R}-\mathrm{O}-\mathrm{R}$ structure element of compound $\mathbf{6}$, benefited by mesomeric effects. Thus, the observed significant negative fragments for EMC are $75 \mathrm{~m} / \mathrm{z}$ for $\mathrm{CH}_{3} \mathrm{CO}_{3}{ }^{-}$and $89 \mathrm{~m} / z$ for $\mathrm{CH}_{3} \mathrm{CH}_{2} \mathrm{CO}_{3}{ }^{-}$(Fig. 3). Furthermore, PCI and NCI data for the already identified compounds 2, 4, 5 and 8 confirmed the results which were obtained by comparison of the EI spectra with NIST 08 (all additional EI, PCI and NCI spectra are presented in the ESI Table $\dagger$ ).

Compounds 9, 10, 19 and 20 in the chromatogram of Fig. 1 are fluoro alkyl phosphates. The structures are presented in Fig. 4.

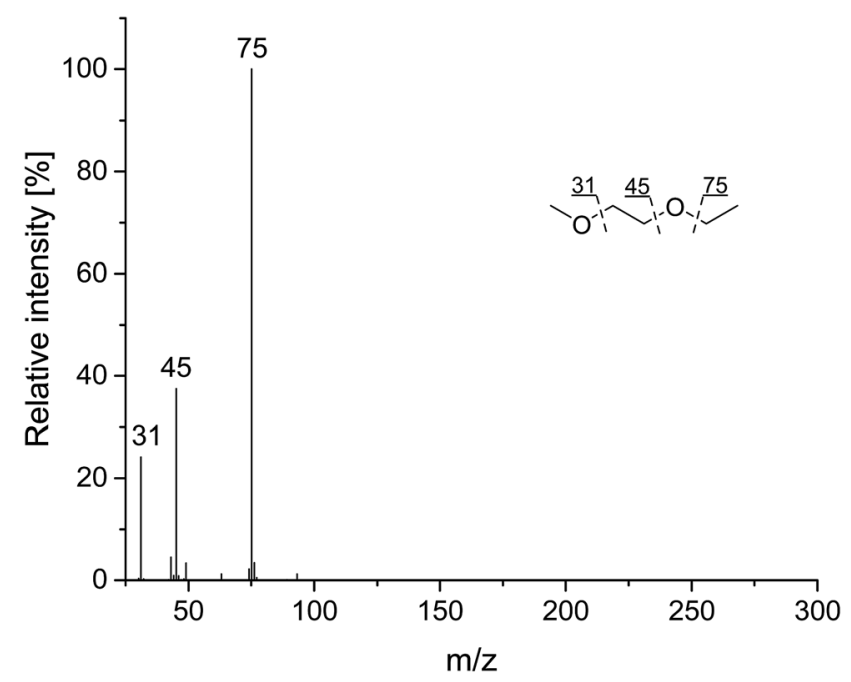

Fig. $2 \mathrm{NCl}$ spectrum of 1-ethoxy-2-methoxy ethane (compound 6 , Table 1) including the corresponding stable fragments with fragmentation pattern.

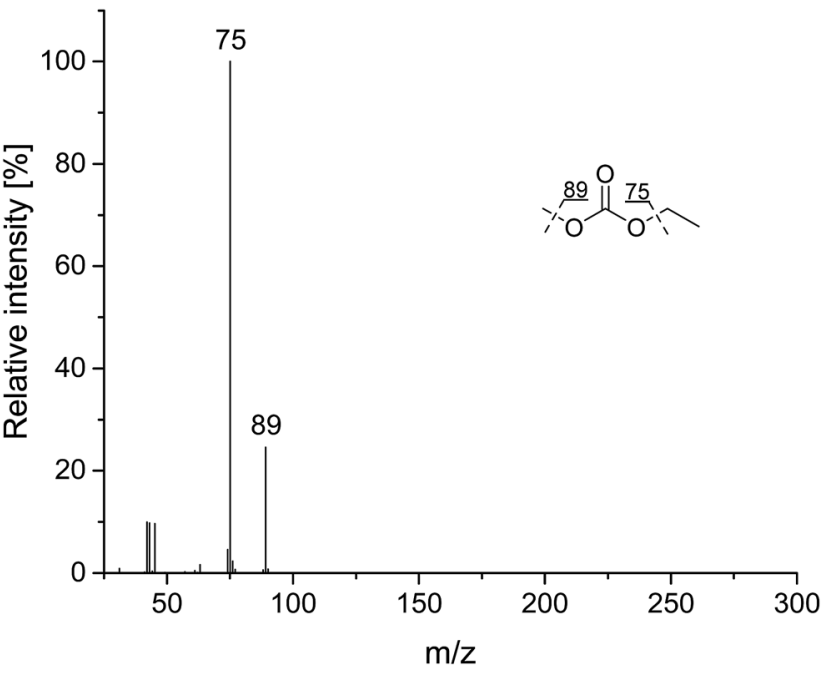

Fig. $3 \mathrm{NCl}$ spectrum of EMC (compound 3, Table 1) including the corresponding stable fragments with fragmentation pattern.

Compounds 12 and 18 were also identified with the NIST 08 library. The remaining analytes of Fig. 1 were studied in the same manner than compound 6 because reference spectra were not available. The combination of EI, PCI and NCI spectra (presented in the ESI Table $\dagger$ ) led to the structures presented in Table 2. Very similar EI spectra and many similar molecular masses made it challenging but NCI gave doubtless evidence about the structures due to significant negative fragments as exemplarily described for compound 6. Furthermore, the retention times differ based on the size and the polarity of the compounds. On the applied non-polar column, small analytes elute first. Moreover, compounds with the organic carbonate structure always elute before the ethylene oxide derivatives. A terminal methyl group leads to a shorter retention time than terminal ethyl groups. The same behavior was observed for a terminal methyl group at the carbonate site compared to the ethylene oxide site. The ratios of the $(\mathrm{M}+\mathrm{H})^{+}$and $\left(\mathrm{M}+\mathrm{NH}_{4}\right)^{+}$ signals can also be taken into account while determining such structures. A decreasing amount of carbonate functional groups in the compound at the same molecular mass and thus more ethylene oxide groups leads to more $(\mathrm{M}+\mathrm{H})^{+}$intensity relative to the $\left(\mathrm{M}+\mathrm{NH}_{4}\right)^{+}$signal. The same behavior occurs with terminal ethyl groups instead of terminal methyl groups.

The two fragments of $77 \mathrm{~m} / \mathrm{z}$ and $91 \mathrm{~m} / z$, respectively, could also be determined as clear structure indicators in the EI spectra from the chromatogram in Fig. 1 which contain an

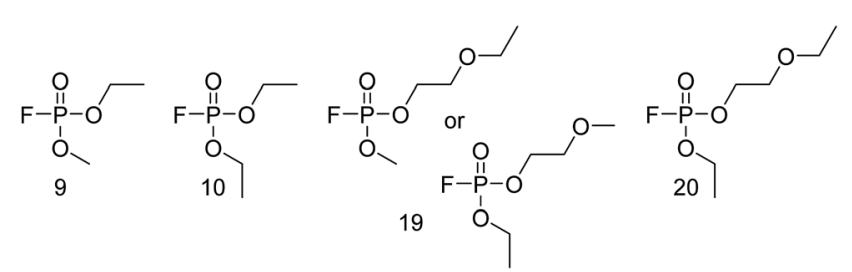

Fig. 4 Structures of detected fluoro alkyl phosphates corresponding to Fig. 1. 
Paper

View Article Online

RSC Advances

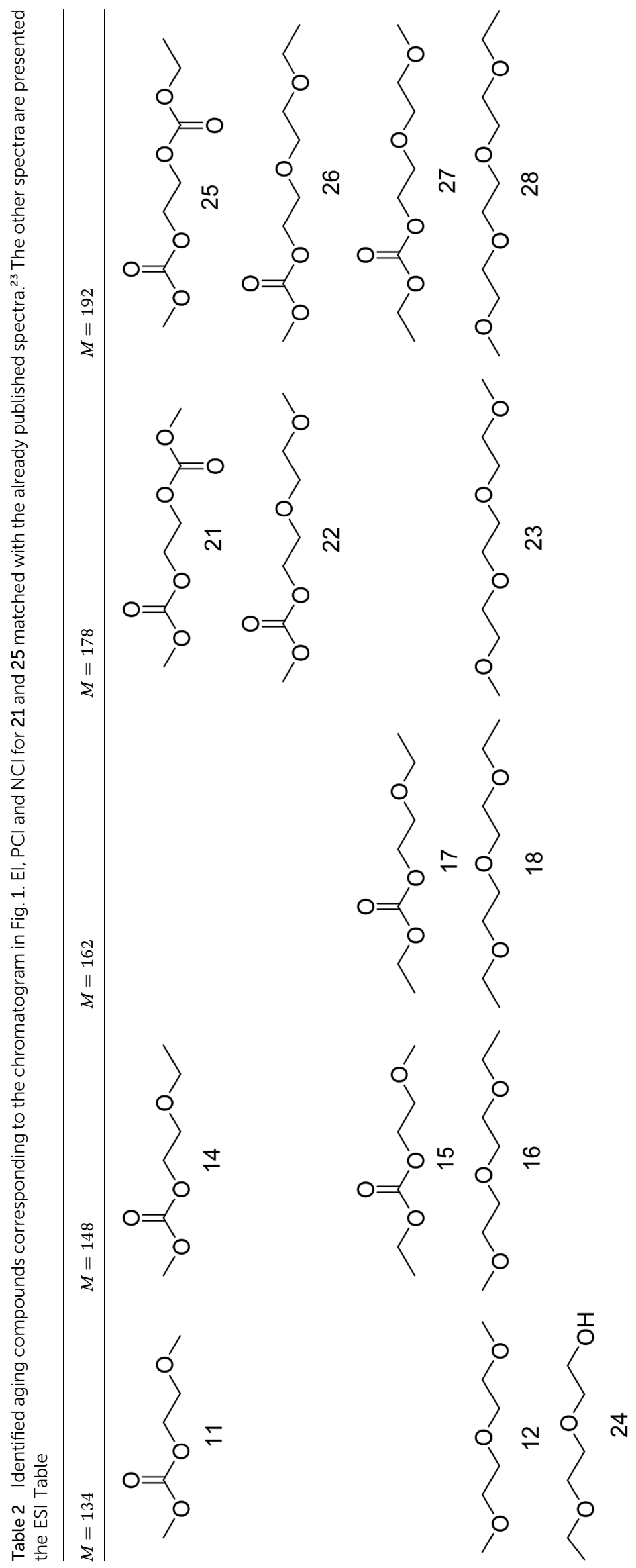

This journal is (C) The Royal Society of Chemistry 2016

RSC Adv., 2016, 6, 57253-57260 | 57257 
organic carbonate functional group with either a terminal methyl or a terminal ethyl group. Wherever possible, formation of the organic aging products was monitored over time. A period of 22 days was investigated. Therefore, an IS [tris $(2,2,2-$ trifluoroethyl) phosphate] was added to the electrolyte solution before each measurement. A separate vial with electrolyte and IS was prepared for each data point. The formed substances can be categorized in three different groups: group one (G1) is consisting of compounds with two organic carbonate functional groups within one molecule. It was not possible to monitor their formation behavior over time due to not completely baseline separated peaks (see compounds 21-28 in Fig. 1). Although, the investigations were carried out with single ion monitoring of compound specific fragments, some peaks are still overlapping due to the almost identical fragmentation of the investigated aging products caused by similar molecular structures. Baseline separation of G1 would have been possible in principal but at the expense of much longer measurement times. However, different equipment (such as 2D GC) which were not available for these experiments would also lead to the intended separation. Additionally, method development with regards to short measurement times at simultaneous baseline separation would be challenging for such approaches as well.

Group two (G2) consists of molecules with a carbonate functional group as well as an ethylene glycol functional group. Their formation behavior over time is presented in Fig. 5a. Fig. 5b depicts the results for the third group (G3) which is composed of substances with oligomeric ethylene glycol chains only. All three groups can be categorized further depending on the substitution pattern of methyl or ethyl groups at their terminals.

Compared to G3, it can be observed that G2 is formed first, starting already after a few days of thermal aging. Especially compounds 11, 14, 15 and $\mathbf{1 7}$ are formed quickly. Compared to the other three substances in G2, they show one ethylene glycol group less. The longer the ethylene glycol chain, the more time is needed for their formation. This leads to the conclusion that the longer chained molecules are formed from the shorter ones which is in good agreement to the formation mechanisms stated in literature. Furthermore, G3 compounds which are consisting of ethylene

a) Group 2:

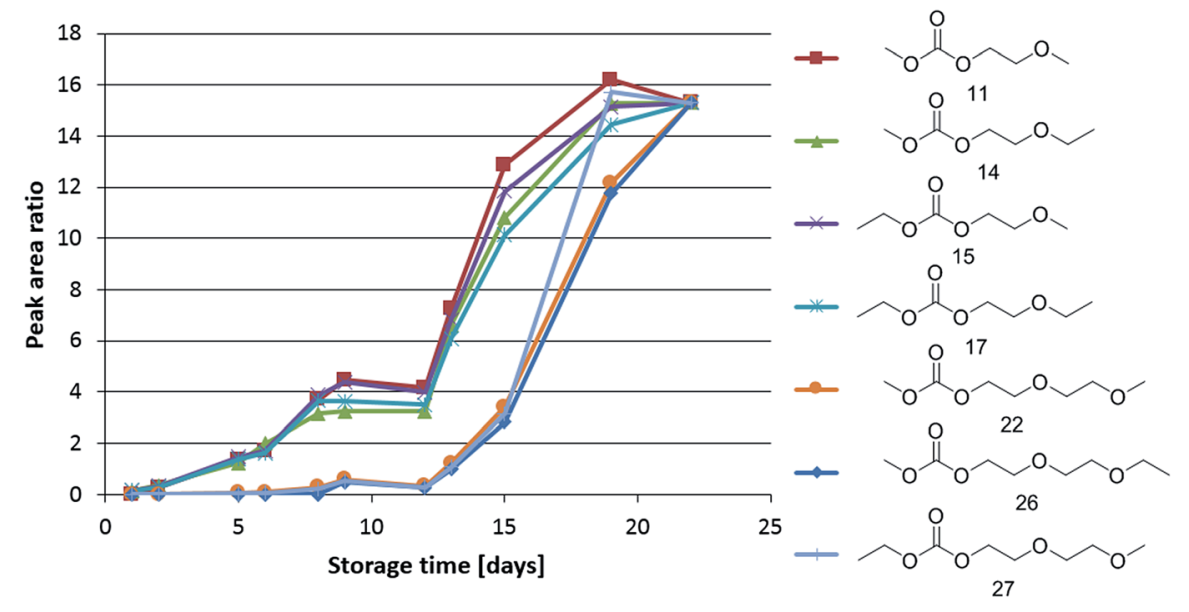

b) Group 3:

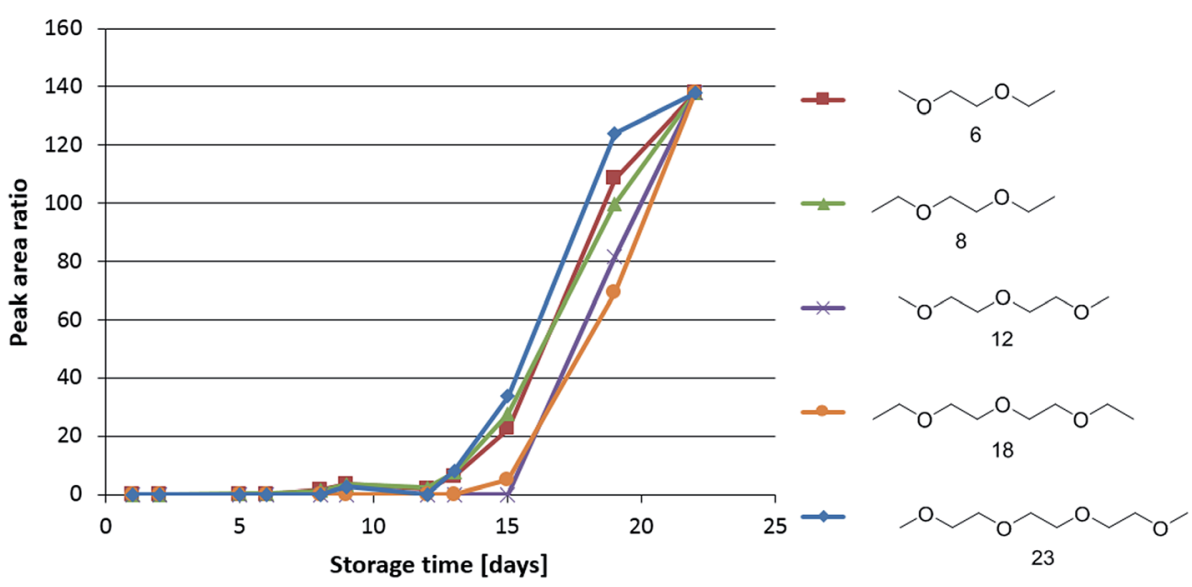

Fig. 5 Formation behavior of organic aging products (a: group 2; b: group 3) over time. Peak area ratios are calculated based on tris(2,2,2trifluoroethyl) phosphate as internal standard. All ratios are normed on the highest value after 22 days for better comparability. Thus, the ratios have to be understood as tendencies and not as absolute values. 
glycol chains only, without organic carbonate functional groups at all, are formed after most of the G2 molecules. The reason is the same as just discussed. For their formation which starts most likely after 13 days, the corresponding compounds from G2 need to be present in the solution in sufficient amounts moreover, it seems that the concentrations for 11, 14, 15 and $\mathbf{1 7}$ are running into a limit after 20 days because they are also consumed. The curve shape in Fig. 5a shows a sigmoidal character. Their formation and consumption to longer chained compounds reaches a steady state. Approximately the same amounts are formed and consumed simultaneously.

\section{Conclusions}

A standard LIB electrolyte (EMC/EC, $1 \mathrm{~mol} \mathrm{~L}^{-1} \mathrm{LiPF}_{6}$ ) was thermally aged at $95{ }^{\circ} \mathrm{C}$ for 22 days and used for method development to detect organic aging products with GC-CI-MS. A complex chromatogram of 28 compounds was obtained. The compounds are very similar in structure, molecular masses and consequently in their fragmentation during EI experiments. The GC method was optimized regarding separation and time. The majority of the obtained peaks could be baseline separated within a measurement time of 12 minutes. Clear structure determination of every compound could be achieved based on the combination of EI with PCI and NCI spectra. The intensity ratios of $(\mathrm{M}+\mathrm{H})^{+}$and $(\mathrm{M}+$ $\left.\mathrm{NH}_{4}\right)^{+}$are furthermore significant structure indicators for this compound family and can be combined with specific fragments of EI, PCI and NCI spectra. After successful identification of the related compounds, the obtained spectra can be used as data base for library search in future aging investigations, which should also include electrochemical experiments to investigate the influence on the occurring reactions. Furthermore, the formation of the aging products was monitored over time. Therefore, samples were investigated in certain time intervals. Relative concentrations were referenced to an IS. Compounds of G2 are formed first compared to G3. Moreover, the shorter molecules of G2 (11, 14, 15 and 17) are already formed in detectable quantities after a few days whereas formation of the other substances in significant amounts takes almost two weeks. Likewise, the longer chained molecules are being formed by the shorter ones which is also proven by the sigmoidal curve shapes.

In comparison to organophosphates, formation of the organic aging products takes more time. The relative quantification with the IS led to the conclusion, that G1-G3 are present in much higher concentrations after 22 days compared to the $\mathrm{P}$ containing compounds. This behavior should be investigated further during electrochemical aging because some fluoro alkyl phosphates which belong to this substance class are highly toxic ${ }^{41-44}$ and information about their concentrations in real LIB cells or their preferred formation under certain conditions are therefore required.

\section{Acknowledgements}

We kindly thank the Federal Ministry for the Environment, Nature Conservation and Nuclear Safety for funding of the project LithoRec II (project grant number: 16EM1025).

\section{References}

1 J. Vetter, P. Novák, M. R. Wagner, C. Veit, K. C. Möller, J. O. Besenhard, M. Winter, M. Wohlfahrt-Mehrens, C. Vogler and A. Hammouche, J. Power Sources, 2005, 147, 269-281.

2 K. Xu, Chem. Rev., 2004, 104, 4303-4418.

3 K. Xu, Chem. Rev., 2014, 114, 115503-115618.

4 V. Aravindan, J. Gnanaraj, S. Madhavi and H.-K. Liu, Chem.Eur. J., 2011, 17, 14326-14346.

5 M. Ue and S. Mori, J. Electrochem. Soc., 1995, 142, 2577-2581.

6 M. Ue, J. Electrochem. Soc., 1994, 141, 3336-3342.

7 S. F. Lux, J. Chevalier, I. T. Lucas and R. Kostecki, ECS Electrochem. Lett., 2013, 242, A121-A123.

8 L. Terborg, S. Weber, F. Blaske, S. Passerini, M. Winter, U. Karst and S. Nowak, J. Power Sources, 2013, 242, 832-837.

9 P. Handel, G. Fauler, K. Kapper, M. Schmuck, C. Stangl, R. Fischer, F. Uhlig and S. Koller, J. Power Sources, 2014, 267, 255-259.

10 H. Yang, G. V. Zhuang and P. N. Ross Jr, J. Power Sources, 2006, 161, 573-579.

11 C. L. Campion, W. Li, W. B. Euler, B. L. Lucht, B. Ravdel, J. F. DiCarlo, R. Gitzendanner and K. M. Abraham, Electrochem. Solid-State Lett., 2004, 7, A194-A197.

12 C. L. Campion, W. Li and B. L. Lucht, J. Electrochem. Soc., 2005, 152, A2327-A2334.

13 V. Kraft, M. Grützke, W. Weber, M. Winter and S. Nowak, J. Chromatogr. A, 2014, 1354, 92-100.

14 B. Vortmann, S. Nowak and C. Engelhard, Anal. Chem., 2013, 85, 3433-3438.

15 W. Weber, V. Kraft, M. Grützke, M. Winter and S. Nowak, J. Chromatogr. A, 2015, 1394, 128-136.

16 M. Grützke, V. Kraft, B. Hoffmann, S. Klamor, J. Diekmann, A. Kwade, M. Winter and S. Nowak, J. Power Sources, 2015, 273, 83-88.

17 V. Kraft, W. Weber, B. Streipert, R. Wagner, C. Schultz, M. Winter and S. Nowak, RSC Adv., 2016, 6, 8-17.

18 W. Weber, R. Wagner, B. Streipert, V. Kraft, M. Winter and S. Nowak, J. Power Sources, 2016, 306, 193-199.

19 V. Kraft, W. Weber, M. Grützke, M. Winter and S. Nowak, RSC Adv., 2015, 5, 80150-80157.

20 J. Barthel and H. J. Gores, Handbook of Battery Materials, Wiley-VCH, Weinheim, 1999.

21 G. Gachot, P. Ribiè̀re, D. Mathiron, S. Grugeon, M. Armand, J.-B. Leriche, S. Pilard and S. Laruelle, Anal. Chem., 2011, 83, 478-485.

22 B. Ravdel, K. M. Abraham, R. Gitzendanner, J. DiCarlo, B. Lucht and C. Campion, J. Power Sources, 2003, 119-121, 805-810.

23 M. Grützke, V. Kraft, W. Weber, C. Wendt, A. Friesen, S. Klamor, M. Winter and S. Nowak, J. Supercrit. Fluids, 2014, 94, 216-222.

24 M. Grützke, X. Mönnighoff, F. Horsthemke, V. Kraft, M. Winter and S. Nowak, RSC Adv., 2015, 5, 43209-43217.

25 L. Terborg, S. Nowak, S. Passerini, M. Winter, U. Karst, P. R. Haddad and P. N. Nesterenko, Anal. Chim. Acta, 2012, 714, 121-126. 
26 M. Grützke, S. Krüger, V. Kraft, B. Vortmann, S. Rothermel, M. Winter and S. Nowak, ChemSusChem, 2015, 8, 3433-3438.

27 L. Gireaud, S. Grugeon, S. Pilard, P. Guenot, J.-M. Tarascon and S. Laruelle, Anal. Chem., 2006, 78, 3688-3698.

28 G. Gachot, S. Grugeon, M. Armand, S. Pilard, P. Guenot, J.-M. Tarascon and S. Laruelle, J. Power Sources, 2008, 178, 409-421.

29 S. E. Sloop, J. K. Pugh, S. Wang, J. B. Kerr and K. Kinoshita, Electrochem. Solid-State Lett., 2001, 4, A42-A44.

30 V. Kraft, M. Grützke, W. Weber, J. Menzel, S. WiemersMeyer, M. Winter and S. Nowak, J. Chromatogr. A, 2015, 1409, 201-209.

31 K. Tasaki, K. Kanda, S. Nakamura and M. Ue, J. Electrochem. Soc., 2003, 150, A1628-A1636.

32 M. Broussely, P. Biensan, F. Bonhomme, P. Blanchard, S. Herreyre, K. Nechev and R. J. Staniewicz, J. Power Sources, 2005, 146, 90-96.

33 T. Kawamura, S. Okada and J.-I. Yamaki, J. Power Sources, 2006, 156, 547-554.

34 H. Yoshida, T. Fukunaga, T. Hazama, M. Terasaki, M. Mizutani and M. Yamachi, J. Power Sources, 1997, 68, 311-315.
35 T. Sasaki, T. Abe, Y. Iriyama, M. Inaba and Z. Ogumi, J. Power Sources, 2005, 150, 208-215.

36 T. Sasaki, T. Abe, Y. Iriyama, M. Inaba and Z. Ogumi, J. Electrochem. Soc., 2005, 152, A2046-A2050.

37 C. Schultz, V. Kraft, M. Pyschik, S. Weber, F. Schappacher, M. Winter and S. Nowak, J. Electrochem. Soc., 2015, 162, A629-A634.

38 G. E. Blomgren, J. Power Sources, 1999, 81-82, 112-118.

39 U. Heider, R. Oesten and M. Jungnitz, J. Power Sources, 1999, 81-82, 119-122.

40 X. Zhang, P. N. Ross, R. Kostecki, F. Kong, S. Sloop, J. B. Kerr, K. Striebel, E. J. Cairns and F. McLarnon, J. Electrochem. Soc., 2001, 148, A463-A470.

41 F. M. Raushel, Nature, 2011, 469, 310-311.

42 http://www.lookchem.com, referenced to Journal of Toxicology and Environmental Health, 1989, 26, 437.

43 http://www.lookchem.com, referenced to Deutsche Gesundheitswesen, 1960, 15, 2179.

44 S. D. Silver, J. Ind. Hyg. Toxicol., 1948, 30, 307-311. 